\title{
BMJ Open Association between engagement in COVID-19-related work and depressive symptoms among hospital workers in a designated COVID-19 hospital in Japan: a cross-sectional study
}

\author{
Yosuke Inoue (D) , ${ }^{1}$ Shohei Yamamoto, ${ }^{1}$ Ami Fukunaga, ${ }^{1}$ Dong Van Hoang, ${ }^{1}$ \\ Takako Miki, ${ }^{1}$ Zobida Islam, ${ }^{1}$ Kengo Miyo, ${ }^{2}$ Masamichi Ishii, ${ }^{2}$ Hironori Ishiwari, ${ }^{2}$ \\ Maki Konishi, ${ }^{1}$ Norio Ohmagari, ${ }^{3}$ Tetsuya Mizoue ${ }^{1}$
}

To cite: Inoue Y, Yamamoto S, Fukunaga A, et al. Association between engagement in COVID-19-related work and depressive symptoms among hospital workers in a designated COVID-19 hospital in Japan: a cross-sectional study. BMJ Open 2021;11:e049996. doi:10.1136/ bmjopen-2021-049996

- Prepublication history for this paper is available online. To view these files, please visit the journal online (http://dx.doi. org/10.1136/bmjopen-2021049996).

Received 10 February 2021 Revised 08 March 2021 Accepted 09 March 2021

Check for updates

(c) Author(s) (or their employer(s)) 2021. Re-use permitted under CC BY-NC. No commercial re-use. See rights and permissions. Published by BMJ.

For numbered affiliations see end of article.

Correspondence to Dr Yosuke Inoue; yosuke.yoshi.yosky@gmail.com

\section{ABSTRACT}

Objectives To examine whether engagement in COVID19-related work was associated with an increased prevalence of depressive symptoms among the staff members working in a designated medical institution for COVID-19 in Tokyo, Japan.

Design A cross-sectional study.

Setting Data were obtained from a health survey conducted in July 2020 among the staff members of a designated medical institution for COVID-19 in Tokyo, Japan.

Participants A total of 1228 hospital workers.

Exposure of interest Engagement in COVID-19-related work (qualitatively (ie, the risk of SARS-CoV-2 infection at work or affiliation to related departments) as well as quantitatively (ie, working hours)) and job categories.

Outcome measures Depressive symptoms.

Results There was no significant association between depressive symptoms and engagement in work with potential exposure to SARS-CoV-2 or affiliation to COVID19-related departments. However, working for longer hours in March/April, when Japan witnessed a large number of infected cases, was significantly associated with depressive symptoms ( $\geq 11$ hours/day: prevalence ratio $(\mathrm{PR})=1.45,95 \% \mathrm{Cl}=1.06$ to 1.99 , compared with $\leq 8$ hours/day). Nurses were more likely to exhibit depressive symptoms than did doctors ( $\mathrm{PR}=1.70,95 \% \mathrm{Cl}=1.14$ to 2.54).

Conclusions This study suggests that the risk of SARSCoV-2 infection at work or having an affiliation to related departments might not be linked with a higher prevalence of depressive symptoms among Japanese hospital workers; contrarily, long working hours appeared to increase the prevalence of depressive symptoms.

\section{INTRODUCTION}

COVID-19, a respiratory illness caused by SARS-CoV-2, has imposed a huge burden on medical and public health systems worldwide. ${ }^{1}$ Besides its enormous direct health consequences (ie, more than 51 million
Strengths and limitations of this study

- We examined if engaging in COVID-19-related work was linked with depressive symptoms among the staff members of one medical institute that was designated for the treatment of serious infectious diseases in Japan.

- As we did not assess information on depressive symptoms before the outbreak, we were unable to judge to what extent the prevalence reported in this study was attributable to the outbreak.

- As the survey was conducted in a designated COVID-19 hospital, the present findings might not be applicable to other hospitals in Japan.

cases with 1.26 million deaths globally as of November 10, 2020), the changes and restrictions in social and economic activities following the spread of COVID-19 have also been linked with worsening of mental health among the general population. ${ }^{2-4}$

To ensure the sustainability of medical and public health systems to contain the outbreak, more attention should be paid to the health conditions of healthcare providers engaging in COVID-19-related work. ${ }^{4-7}$ A meta-analysis by Pappa et at reported the prevalence of anxiety and depression to be $23.2 \%$ and $22.5 \%$, respectively, among medical workers engaging in COVID-19-related work. Notably, a wide range of psychological and physiological stressors, including the risk of nosocomial infections, shortage of personal protective equipment, increased workload and social stigma, may place them at a higher risk of negative mental health outcomes. ${ }^{59}$

This study extends these previous studies by examining whether the COVID-19related work was associated with depressive 
symptoms in Japan. Although the number of COVID19-related deaths remains smaller in Japan than those reported in the more severely affected countries, yet the Japanese medical and public health resources have been overwhelmed by the screening and treatment of patients with COVID-19. ${ }^{10}$ In addition, there have been numerous reports of healthcare workers facing discrimination and harassment in Japan (eg, their children refused access to nursery school). ${ }^{11}$ It is possible that work-family conflicts may have emerged due to increased workload, affecting the mental health of healthcare providers. ${ }^{8}$

Therefore, this study aimed to examine whether engaging in COVID-19-related work (qualitatively (ie, the risk of SARS-CoV-2 infection at work or affiliation to related departments) as well as quantitatively (ie, working hours)) and job categories were linked with an increased prevalence of depressive symptoms among the staff members working in a designated medical institution for COVID-19 in Tokyo, Japan. To inform better efforts to reduce psychological burden among staff members, we also conducted subgroup analyses among doctors and nurses (ie, the two largest job categories in this analytic sample).

\section{METHODS}

\section{Study participants}

A health survey was conducted in July 2020 among the staff members of National Center for Global Health and Medicine, Japan (NCGM), in which we analysed COVID-19 antibodies and collected questionnaire-based information on lifestyles and depressive symptoms. ${ }^{12}$ As one of the designated medical institutions in Tokyo for the Category II infectious diseases (eg, tuberculosis, Middle East respiratory syndrome and COVID-19) under the Infectious Diseases Control Law, the NCGM conducted screening and treatment of COVID-19 since the beginning of epidemic in Japan. As of July 2020, no staff members died of COVID-19-related illness and no cluster of nosocomial infections were reported.

A total of 1579 staff members were invited for the survey, of which 1228 agreed to participate (353 men and 875 women; participation rate: $77.8 \%$ ). The questionnaire was administered and the information was collected online using Microsoft Forms. The participants took approximately $16 \mathrm{~min}$ to complete the questionnaire.

Informed consent was obtained from all included study participants.

\section{Outcomes}

Depressive symptoms were assessed using the following two questions that were employed in the Two-Question case-finding Instrument $(\mathrm{TQI})^{13}$ : 'During the past month, have you often been bothered by feeling down or depressed?'; and 'During the past month, have you often been bothered by little interest or pleasure in doing things?'. In the original TQI, which was developed to have high sensitivity for a screening purpose (pooled sensitivity: 95\%; pooled specificity: $65 \%),{ }^{14}$ depressive symptoms were defined when respondents answered 'yes' to either of the questions (ie, TQI score of $\geq 1$ ). However, to reduce the proportion of false negative in this study, we defined depressive symptoms only when participants answered in the affirmative to both questions (ie, TQI score of 2). A previous study in non-COVID-19-related subjects in Japan reported a sensitivity and specificity of $87.9 \%$ and $81.4 \%^{15}$ at the TQI score of 2; while another Japanese study reported those as $75 \%$ and $88.2 \%{ }^{16}$

\section{Exposures}

The following two self-reported questions were used to assess the extent to which participants were possibly exposed to SARS-CoV-2: 'Have you ever engaged in COVID-19-related work?' and 'Did you engage in any work in which you were heavily exposed to SARS-CoV-2?'. Participants were categorised into three groups as follows: low (ie, those who did not engage in COVID-19-related work), middle (ie, those who engaged in COVID-19related work without heavy exposure to the virus) and high risk of SARS-CoV-2 infection at work (ie, those who were heavily exposed to SARS-CoV-2). Those who reported to engaged in the related work but were not involved in patient care or specimen management were classified into the low-exposure group.

To assess the association in relation to the quantitative aspect of COVID-19-related work, we also collected selfreported information on working hours from late March to mid-April 2020 during the first wave of the outbreak in Japan. Response options included $\leq 6,7,8,9,10,11,12$, 13 and $\geq 14$ hours/day, which were categorised into the following three groups: $\leq 8,9-10$ or $\geq 11$ hours/day.

We also obtained information on job type (doctors, nurses, allied healthcare professionals, administrative staffs, researchers and management) and department from the labour management office of NCGM. As for the former, we combined administrative staffs, researchers and management into one category 'others' due to their small individual sample size. Regarding the latter, the department was used to categorise participants into three groups: those working for COVID-19-related medical departments, the other medical departments; and nonmedical departments.

\section{Covariates}

Information on the following covariates was collected via the questionnaire: age (in years), sex (male, female), current smoking status, daily alcohol consumption, physical activity, co-morbid conditions and sleep duration (in hours).

Smoking status was defined when participants smoked cigarettes or heat-not-burn cigarettes (never/current/ former smoker). Daily alcohol consumption was estimated based on questionnaire information; we followed the lead of previous epidemiological studies ${ }^{17}$ and assigned the following values to each response options for consumption frequency (do not drink $=0$, quit drinking $=0,1-3$ days $/$ month $=0.5,1-2$ days $/$ week $=1.5,3-4$ days $/$ week $=3.5$, 
5-6 days/week $=5.5$ and everyday drinking=7), which were then multiplied with the amount consumed per day (ie, $0.5 ; 1 ; 1.5 ; 2 ; 2.5 ; 3 ; 3.5$ and $\geq 4$ drinks (calculated as four drinks); one drink is equivalent to 1 go, a Japanese traditional unit, which contains approximately $23 \mathrm{~g}$ of ethanol). We then grouped the participants into the following four categories based on their daily consumption: do not drink; $<1 ; 1-1.9$ and $\geq 2$ drinks/day. Leisuretime physical activity was assessed with three questions regarding time spent per week in indoor physical activity, outdoor physical activity during daytime and outdoor physical activity during night-time. Response options included: never; <30 min; 30-59 min; 1-1.9 hours; 2-2.9 hours; 3-3.9 hours and $\geq 4$ hours; following the lead of a previous study, ${ }^{18}$ in which the midpoint of range was used as a proxy score of each frequency category, we assigned the values of $0,15,45,90,150,210$ and $270 \mathrm{~min} /$ week to each category, respectively. We calculated the total time spent in physical activity and categorised participants into the following categories (none, $<60,60-119,120-179$ or $\geq 180 \mathrm{~min}$ (week).

Co-morbid conditions were assessed by enumerating the total number of the following conditions, which were known to increase the risk of developing severe COVID-19 cases, that is, diabetes, hypertension, chronic obstructive pulmonary disease, heart disease, cerebrovascular disease, cancer, other chronic diseases and obesity (defined as BMI $\geq 30 \mathrm{~kg} / \mathrm{m}^{2}$ based on self-reported weight and height), which was categorised into three groups $(0$, 1 and $\geq 2$ ). Response options for sleeping hours in the previous 1 month were: $<4 ; 4-4.9 ; 5-5.9 ; 6-6.9 ; 7-7.9$; $\geq 8$ hours, which were categorised into three groups $(<6$; $6-6.9$ and $\geq 7$ hours).

\section{Statistical analysis}

A Poisson regression analysis with a robust variance estimator ${ }^{19}{ }^{20}$ was used to investigate the association between exposure variables (ie, the risk of SARS-CoV-2 infection at work, affiliation to COVID-19-related departments, job categories and working hours in March and April 2020) and depressive symptoms. Model 1 was adjusted for age, sex, current smoking status, daily alcohol consumption, physical activity and co-morbid conditions, while model 2 was additionally adjusted for sleep duration. The exposure variables were mutually adjusted in the models. We calculated the $\mathrm{p}$ value for trend in relation to the degree of potential exposure to SARS-CoV-2; department affiliation and working hours, using the 'contrast' command in Stata.

To examine if the abovementioned associations are similar across different job categories, we also conducted a set of analysis while confining the analytic sample to (1) doctors or (2) nurses (ie, the two largest job categories in this analytic sample).

Results are presented in the form of prevalence ratios (PRs) with corresponding 95\% CIs. All the analyses were conducted using Stata V. 16.1 (StataCorp). The level of significance was set at $\mathrm{p}<0.05$ (two-sided).
Patients and public involvement

Patients and the public were not involved in this study.

\section{RESULTS}

Among the 1228 participants, 268 (21.8\%) reported depressive symptoms. Table 1 shows the basic characteristics of study participants. The mean age was 36.0 $(\mathrm{SD}=11.0)$ years and $71.3 \%$ of participants were woman. Doctors, nurses and allied healthcare professionals comprised $20.4 \%, 49.6 \%$, and $12.7 \%$ of study participants, respectively.

Table 2 shows the results of the Poisson regression model examining the association between engagement in COVID-19-related work and depressive symptoms. There was no statistically significant association between depressive symptoms and the risk of SARS-CoV-2 infection at work or department affiliation. For example, compared with those in the lowest risk category, the PRs of depressive symptoms were 0.87 (95\% CI=0.68 to 1.11 ) and 0.97 (95\% CI=0.73 to 1.29$)$ for those in the middle and highest categories, respectively. Conversely, working for longer hours in March and April 2020 was statistically associated with an increased prevalence of depressive symptoms $(\geq 11$ hours/day: $\mathrm{PR}=1.45,95 \% \mathrm{CI}=1.06$ to 1.99 , compared with $\leq 8$ hours/day). Additionally, nurses were more likely to have depressive symptoms $(\mathrm{PR}=1.70$, 95\% CI=1.14 to 2.54) than did doctors. Furthermore, these results did not change when the model was further adjusted for sleep duration.

Table 3 shows subgroup analyses in which we confined our analytic sample to only doctors or nurses. It was revealed that longer working hours were linked with a higher prevalence of depressive symptoms among nurses ( $\mathrm{PR}=1.77,95 \% \mathrm{CI}=1.21$ to 2.59$)$ but not among doctors ( $\mathrm{PR}=1.20,95 \% \mathrm{CI}=0.51$ to 2.83$)$. In contrast, the risk of SARS-CoV-2 infection at work tended to increase the prevalence of depressive symptoms among doctors (model 1: PR=2.69, 95\% CI=0.97 to 7.51; $\mathrm{p}_{\text {trend }}=0.048$ ) but not among nurses $(\mathrm{PR}=0.91,95 \% \mathrm{CI}=0.63$ to 1.32$)$. While it did not reach statistical significance, the affiliation to COVID-19-related department was rather linked with a lower prevalence of depressive symptoms among doctors $(\mathrm{PR}=0.34,95 \% \mathrm{CI}=0.09$ to 1.25$)$.

\section{DISCUSSION}

In this survey on 1228 hospital workers in a designated COVID-19 hospital in Japan, we did not find any evidence of statistically significant association between engagement in COVID-19-related work and depressive symptoms. However, we found a statistically significant association of depressive symptoms with working hours in late March to mid-April 2020. Additionally, a higher prevalence of depressive symptoms was observed in nurses versus doctors.

Importantly, the null finding in relation to the association between COVID-19-related work (ie, the risk of SARS-CoV-2 infection at work and affiliation to related 
Table 1 Basic characteristics of study participants in a designated COVID-19 hospital in Tokyo, Japan (2020)

\begin{tabular}{|c|c|c|c|c|}
\hline & & $\begin{array}{l}\text { Participants } \\
\text { at work }\end{array}$ & ording to the & CoV-2 infection \\
\hline Female, n (\%) & $875(71.3)$ & $339(83.1)$ & $328(68.6)$ & $208(60.8)$ \\
\hline Job categories, n (\%) & & & & \\
\hline Nurses & $609(49.6)$ & $211(51.7)$ & $225(47.1)$ & $173(50.6)$ \\
\hline Allied healthcare professionals & $156(12.7)$ & $21(5.1)$ & $73(15.3)$ & $62(18.1)$ \\
\hline Others & $213(17.3)$ & $104(25.5)$ & $90(18.8)$ & $19(5.6)$ \\
\hline Affiliated departments, $\mathrm{n}(\%)$ & & & & \\
\hline COVID-19-related departments & $128(10.4)$ & $27(6.6)$ & $16(3.3)$ & $85(24.9)$ \\
\hline$\leq 8$ hours/day & $663(54.0)$ & $210(51.5)$ & $261(54.6)$ & $192(56.1)$ \\
\hline 9-10 hours/day & $420(34.2)$ & $154(37.7)$ & 167 (34.9) & $99(29.0)$ \\
\hline$\geq 11$ hours/day & $145(11.8)$ & $44(10.8)$ & $50(10.5)$ & $51(14.9)$ \\
\hline Smoking status, n (\%) & & & & \\
\hline Never & $1061(86.4)$ & $371(90.9)$ & $394(82.4)$ & $296(86.5)$ \\
\hline Former & $101(8.2)$ & $21(5.1)$ & $52(10.9)$ & $28(8.2)$ \\
\hline Current & $66(5.4)$ & $16(3.9)$ & $32(6.7)$ & $18(5.3)$ \\
\hline Alcohol consumption, n (\%) & & & & \\
\hline Do not drink & $362(29.5)$ & $138(33.8)$ & $132(27.6)$ & $92(26.9)$ \\
\hline 60-119 min/week & $202(16.4)$ & $78(19.1)$ & $80(16.7)$ & $44(12.9)$ \\
\hline $120-179 \mathrm{~min} /$ week & $71(5.8)$ & $23(5.6)$ & $21(4.4)$ & $27(7.9)$ \\
\hline$\geq 180 \mathrm{~min} /$ week & $233(19.0)$ & $59(14.5)$ & $98(20.5)$ & $76(22.2)$ \\
\hline Sleeping hours, n (\%) & & & & \\
\hline$<6$ hours/day & $544(44.3)$ & $170(41.7)$ & $218(45.6)$ & $156(45.6)$ \\
\hline $6-6.9$ hours/day & $491(40.0)$ & $171(41.9)$ & $194(40.6)$ & $126(36.8)$ \\
\hline$\geq 7$ hours/day & $193(15.7)$ & $67(16.4)$ & $66(13.8)$ & $60(17.5)$ \\
\hline The number of co-morbid conditio & & & & \\
\hline 0 & $1007(82.0)$ & $342(83.8)$ & $389(81.4)$ & $276(80.7)$ \\
\hline 1 & $168(13.7)$ & $53(13.0)$ & $65(13.6)$ & $50(14.6)$ \\
\hline$\geq 2$ & $53(4.3)$ & $13(3.2)$ & $24(5.0)$ & $16(4.7)$ \\
\hline
\end{tabular}

${ }^{*}$ One drink is equivalent to $1 \mathrm{go}$, that is, a Japanese traditional unit containing approximately $23 \mathrm{~g}$ of ethanol.

department) and depressive symptoms in this study was inconsistent with a series of studies that reported increased odds/prevalence of depressive symptoms among hospital workers with versus without direct exposure to the virus. ${ }^{21-26}$ However, it is in line with a few other studies. ${ }^{27}{ }^{28}$ In addition, although for a different outcome (ie, post-traumatic stress symptoms), there was one study in Japan that did not find the evidence of a statistically significant association in relation to contact with a patient with COVID-19 among 331 members of the Disaster Medical Assistance Team engaging in quarantine and treatment of COVID-19. ${ }^{29}$ 
Table 2 Results of a Poisson regression model with a robust variance estimator examining the association between engagement in COVID-19-related work and depressive symptoms among study participants working at a designated COVID-19 hospital in Tokyo, Japan (2020)

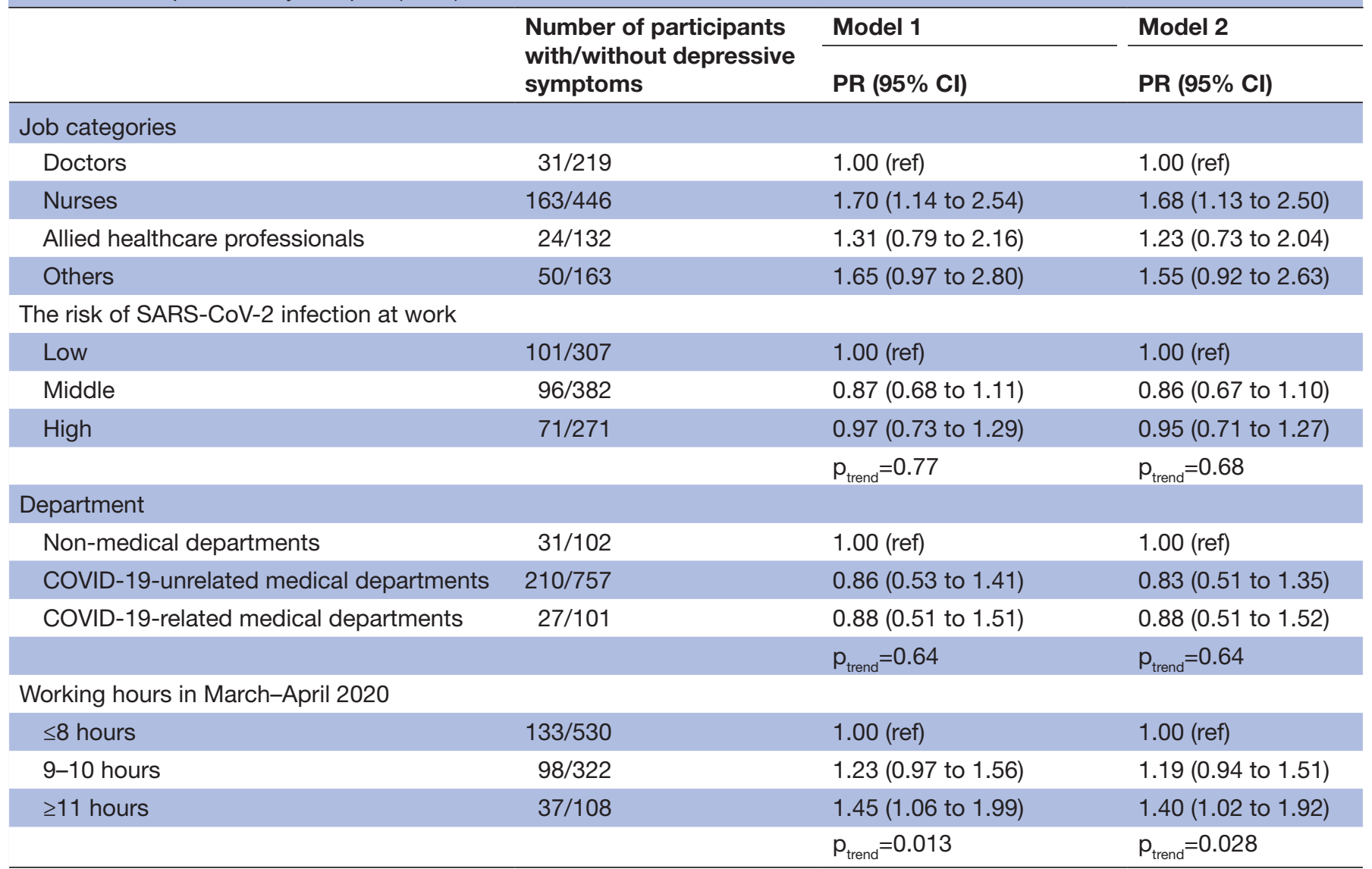

Results are shown in the form of prevalence ratios (PRs) with corresponding 95\% confidence intervals (Cls).

Model 1 was adjusted for age, sex, smoking status, alcohol consumption, physical activity and co-morbid conditions. Model 2 was further adjusted for sleep duration. The exposure variables were mutually adjusted in the models.

Several interpretations are possible for the null finding observed in our study. First, it is possible that the situation regarding COVID-19 was not as severe as in China ${ }^{21-24}$ or Italy, ${ }^{25}$ where increased risk of depressive symptoms associated with the COVID-19-related work was reported. As described earlier, there were no COVID-19-related mortality cases among staff members or cluster of nosocomial infection in the NCGM hospital. Second, given the widespread effects of COVID-19, even those who did not engage in COVID-19-related work might have also felt stressed/depressed via sources other than work at hospital, which could have blurred the differences between those who engaged in COVID-19-related work and those who did not. This might also explain the findings of Wang et $a l^{28}$ who reported that depression was prevalent in both frontline $(36.6 \%)$ and non-frontline $(35.6 \%)$ medical workers in Hubei, China $(p=0.70)$. Third, since the hospital was designated to provide special care for the infectious diseases, the staff members might have been well prepared to this kind of emergency and thus, might not have been affected by the work.

While working hours have not been widely used as a predictor of negative mental health outcomes in previous studies conducted among healthcare workers in the midst of epidemic outbreaks, ${ }^{7}$ the significant association between working hours and depressive symptoms observed in our study was in line with a broader body of existing literature on the association between working hours and depressive symptoms in general. ${ }^{30}$ It is possible that stressors with quantitative nature might have affected the psychological well-being more than the stressors with qualitative nature in this specific context, which was more pronounced among nurses, according to the subgroup analysis.

Compared with doctors, nurses had a higher prevalence of depressive symptoms in our study. Previous studies have reported that doctors/physicians are less affected by epidemic outbreak ${ }^{7}$ but with some exceptions. ${ }^{31}$ Possible interpretations for our findings that nurses experienced more depressive symptoms than doctors include: less job control (high job strain), engaging in night shift work more frequently ${ }^{32}$ and more time and contact with infected patients. It is also possible that given that female workers comprised mostly nurses in this study sample, as a result of gender role expectations placed on females in Japan, ${ }^{8}$ female nurses might have struggled more frequently with work-life balance than male workers (ie, residual confounding). 
Table 3 Subgroup analyses confining study participants to doctors or nurses working in a designated COVID-19 hospital in Tokyo, Japan (2020)

\begin{tabular}{lll}
$\begin{array}{l}\text { Number of participants } \\
\text { with/without depressive } \\
\text { symptoms }\end{array}$ & Model 1 & Model 2 \\
\cline { 2 - 3 } & PR $(95 \% \mathrm{Cl})$ & PR $(95 \% \mathrm{Cl})$
\end{tabular}

Doctors ( $\mathrm{n}=\mathbf{2 5 0}$ )

The risk of SARS-CoV-2 infection at work

\begin{tabular}{|c|c|c|c|}
\hline Low & $7 / 65$ & 1.00 (ref) & 1.00 (ref) \\
\hline Middle & $10 / 80$ & 1.16 (0.43 to 3.12$)$ & 1.19 (0.43 to 3.27$)$ \\
\hline \multirow[t]{2}{*}{ High } & $14 / 74$ & 2.69 (0.97 to 7.51$)$ & 2.89 (1.00 to 8.39$)$ \\
\hline & & $p_{\text {trend }}=0.048$ & $p_{\text {trend }}=0.042$ \\
\hline \multicolumn{4}{|l|}{ Department affiliation } \\
\hline COVID-19-unrelated departments & $29 / 189$ & 1.00 (ref) & 1.00 (ref) \\
\hline COVID-19-related medical departments & $2 / 30$ & 0.34 (0.09 to 1.25$)$ & $0.32(0.09$ to 1.18$)$ \\
\hline \multicolumn{4}{|l|}{ Working hours in March-April 2020} \\
\hline$\leq 8$ hours & $10 / 75$ & 1.00 (ref) & 1.00 (ref) \\
\hline $9-10$ hours & $13 / 96$ & 1.31 (0.60 to 2.87 ) & 1.20 (0.55 to 2.62$)$ \\
\hline \multirow[t]{2}{*}{$\geq 11$ hours } & $8 / 48$ & $1.20(0.51$ to 2.83$)$ & $1.06(0.43$ to 2.60$)$ \\
\hline & & $p_{\text {trend }}=0.63$ & $p_{\text {trend }}=0.85$ \\
\hline
\end{tabular}

Nurses $(n=609)$

The risk of SARS-CoV-2 infection at work

\begin{tabular}{|c|c|c|c|}
\hline Low & $63 / 148$ & 1.00 (ref) & 1.00 (ref) \\
\hline Middle & $51 / 174$ & 0.80 (0.57 to 1.11$)$ & 0.83 (0.59 to 1.15$)$ \\
\hline \multirow[t]{2}{*}{ High } & $49 / 124$ & 0.91 (0.63 to 1.32) & $0.92(0.64$ to 1.34$)$ \\
\hline & & $p_{\text {trend }}=0.57$ & $p_{\text {trend }}=0.63$ \\
\hline \multicolumn{4}{|l|}{ Department affiliation } \\
\hline COVID-19-unrelated departments & $144 / 409$ & 1.00 (ref) & 1.00 (ref) \\
\hline COVID-19-related medical departments & $19 / 37$ & 1.35 (0.85 to 2.13$)$ & 1.35 (0.85 to 2.14$)$ \\
\hline \multicolumn{4}{|l|}{ Working hours in March-April 2020} \\
\hline$\leq 8$ hours & $77 / 253$ & 1.00 (ref) & 1.00 (ref) \\
\hline $9-10$ hours & $64 / 161$ & $1.23(0.91$ to 1.66$)$ & 1.17 (0.86 to 1.57$)$ \\
\hline \multirow[t]{2}{*}{$\geq 11$ hours } & $22 / 32$ & 1.77 (1.21 to 2.59$)$ & 1.65 (1.12 to 2.42$)$ \\
\hline & & $\mathrm{p}_{\text {trend }}=0.010$ & $p_{\text {trend }}=0.033$ \\
\hline
\end{tabular}

Results are shown in the form of prevalence ratios (PRs) with corresponding 95\% confidence intervals (Cls).

Model 1 was adjusted for age, sex, smoking status, alcohol consumption, physical activity and co-morbid conditions. Model 2 was further adjusted for sleeping hours. The exposure variables were mutually adjusted in the models.

Categories of department affiliation were combined to form COVID-19-related department and COVID-19-unrelated departments (ie, nonCOVID-19-related medical departments and non-medical departments) due to small sample size.

Interestingly, the subgroup analyses suggested that doctors and nurses were psychologically affected by different determinants. More specifically, long working hours, and not the risk of SARS-CoV-2 infection at work, were linked with a higher prevalence of depressive symptoms among nurses, while the opposite was observed among doctors. This difference could be the focus of future studies as such differences should be considered when implementing programmes to mitigate the psychological burden among hospital workers working in the midst of epidemiologic outbreaks.

\section{Limitations}

There are several limitations that should be addressed. First, depressive symptoms were assessed via two questions ${ }^{15} 16$ and were not based on diagnoses by psychiatrists. Second, as we did not assess information on depressive symptoms before the outbreak, we were unable to judge to what extent the prevalence reported in this study was attributable to the outbreak or increased associated burden. Third, the survey was conducted in July 2020, when the situation was settled, which might be different from the association that would have been reported in 
March/April. For example, it is possible that those who were depressed due to COVID-19-related work had recovered. Fourth, there are several variables that could have explained the association between engaging in COVID19-related work and depressive symptoms (eg, social support, job control, availability of protective equipment and socioeconomic status). Sixth, some questionnaire information was subject to misclassification bias. Lastly, the survey was conducted in one medical institute that was designated for the treatment of serious infectious diseases. Thus, the present findings might not be applicable to other hospitals in Japan.

\section{CONCLUSION}

This study suggests that the risk of SARS-CoV-2 infection at work or having an affiliation to related departments might not have necessarily been linked with a higher prevalence of depressive symptoms among hospital workers in Japan. Our results contradict similar reports on hospital workers from the more severely affected countries although they are consistent with those reported in another Japanese study in the midst of the COVID-19 pandemic. This highlights that the medical professionals in different countries may have different mental health needs according to the local situation and preparedness.

\section{Author affiliations}

${ }^{1}$ Department of Epidemiology and Prevention, Center for Clinical Sciences, National Center for Global Health and Medicine, Shinjuku-ku, Tokyo, Japan

${ }^{2}$ Center for Medical Informatics Intelligence, National Center for Global Health and Medicine, Shinjuku-ku, Tokyo, Japan

${ }^{3}$ Disease Control and Prevention Center, National Center for Global Health and Medicine, Shinjuku-ku, Tokyo, Japan

Acknowledgements The authors thank study participants and staff members of NCGM who supported this survey.

Contributors All the authors contributed to the conception, design and interpretation of data. $\mathrm{Yl}, \mathrm{SY}$ and $\mathrm{AF}$ contributed to data analysis. $\mathrm{KM}, \mathrm{MI}, \mathrm{HI}$ and $\mathrm{MK}$ contributed to the acquisition of data. DVH, TM, ZI, NO and TM contributed to critical revision of the manuscript.

Funding This study was financially supported by the NCGM COVID-19 Gift Fund (Grant No: not applicable) and the Japan Health Research Promotion Bureau Research Fund (Grant No: 2020-B-09).

Competing interests None declared.

Patient and public involvement Patients and/or the public were not involved in the design, or conduct, or reporting, or dissemination plans of this research.

Patient consent for publication Not required.

Ethics approval The study procedure was in accordance with the 1964 Helsinki declaration and its later amendments and was approved by the NCGM Ethics Committee (approval number: NCGM-G-003598-00).

Provenance and peer review Not commissioned; externally peer reviewed.

Data availability statement No data are available. The dataset has ethical restrictions for public deposition but is available from the corresponding author on reasonable request.

Open access This is an open access article distributed in accordance with the Creative Commons Attribution Non Commercial (CC BY-NC 4.0) license, which permits others to distribute, remix, adapt, build upon this work non-commercially, and license their derivative works on different terms, provided the original work is properly cited, appropriate credit is given, any changes made indicated, and the use is non-commercial. See: http://creativecommons.org/licenses/by-nc/4.0/.
ORCID iD

Yosuke Inoue http://orcid.org/0000-0002-7690-3447

\section{REFERENCES}

1 WHO coronavirus disease (COVID-19) Dashboard. Available: https:// covid19.who.int [Accessed 15 Aug 2020].

2 Rajkumar RP. COVID-19 and mental health: a review of the existing literature. Asian J Psychiatr 2020;52:102066.

3 Galea S, Merchant RM, Lurie N. The mental health consequences of COVID-19 and physical distancing: the need for prevention and early intervention. JAMA Intern Med 2020;180:817-8.

4 Luo M, Guo L, Yu M, et al. The psychological and mental impact of coronavirus disease 2019 (COVID-19) on medical staff and general public - A systematic review and meta-analysis. Psychiatry Res 2020;291:113190.

5 World Health Organization. Mental health and psychosocial considerations during the COVID-19 outbreak. Available: https:// www.who.int/publications-detail-redirect/WHO-2019-nCoVMentalHealth-2020.1 [Accessed 15 Aug 2020].

6 Pappa S, Ntella V, Giannakas T, et al. Prevalence of depression, anxiety, and insomnia among healthcare workers during the COVID-19 pandemic: a systematic review and meta-analysis. Brain Behav Immun 2020;88:901-7.

7 Preti E, Di Mattei V, Perego G, et al. The psychological impact of epidemic and pandemic outbreaks on healthcare workers: rapid review of the evidence. Curr Psychiatry Rep 2020;22.

8 Makino M, Kanie A, Nakajima A, et al. Mental health crisis of Japanese health care workers under COVID-19. Psychol Trauma 2020;12:S136-7.

9 Kang L, Li Y, Hu S, et al. The mental health of medical workers in Wuhan, China dealing with the 2019 novel coronavirus. Lancet Psychiatry 2020;7:e14.

10 Japan COVID-19 coronavirus Tracker. Available: https:// covid19japan.com/ [Accessed 15 Aug 2020].

11 The Japan Nursing Ethics Association. Show respect to health care workers who are fighting the novel coronavirus. Available: http://jnea. net/pdf/200403-covid.pdf

12 Tanaka A, Yamamoto S, Miyo K. Seroprevalence of antibodies against SARS-CoV-2 in a large national hospital and affiliated facility in Tokyo, Japan. Journal of Infection 2021;108.

13 Whooley MA, Avins AL, Miranda J, et al. Case-Finding instruments for depression. two questions are as good as many. J Gen Intern Med 1997;12:439-45.

14 Bosanquet K, Bailey D, Gilbody S, et al. Diagnostic accuracy of the Whooley questions for the identification of depression: a diagnostic meta-analysis. BMJ Open 2015;5:e008913.

15 Suzuki T. Evaluation of questionnaires (Two-question case-finding instruments \& Beck Depression Inventory) as a tools for screening and intervention in work place. Seishin Igaku 2003;45:699-708.

16 Adachi Y, Aleksic B, Nobata R, et al. Combination use of Beck depression inventory and two-question case-finding instrument as a screening tool for depression in the workplace. BMJ Open 2012;2:e000596.

17 Iso H, Baba S, Mannami T, et al. Alcohol consumption and risk of stroke among middle-aged men: the JPHC study cohort I. Stroke 2004;35:1124-9.

18 Inoue M, Iso $\mathrm{H}$, Yamamoto $\mathrm{S}$, et al. Daily total physical activity level and premature death in men and women: results from a largescale population-based cohort study in Japan (JPHC study). Ann Epidemiol 2008;18:522-30.

19 Greenland S. Model-based estimation of relative risks and other epidemiologic measures in studies of common outcomes and in case-control studies. Am J Epidemiol 2004;160:301-5.

20 Zou G. A modified poisson regression approach to prospective studies with binary data. Am J Epidemiol 2004;159:702-6.

21 Lai J, Ma S, Wang Y, et al. Factors associated with mental health outcomes among health care workers exposed to coronavirus disease 2019. JAMA Netw Open 2020;3:e203976.

22 Liu Y, Wang L, Chen L, et al. Mental health status of paediatric medical workers in China during the COVID-19 outbreak. Front Psychiatry 2020;11:702.

23 Lu W, Wang H, Lin Y, et al. Psychological status of medical workforce during the COVID-19 pandemic: a cross-sectional study. Psychiatry Res 2020;288:112936.

24 Wang $\mathrm{H}$, Huang $\mathrm{D}$, Huang $\mathrm{H}$, et al. The psychological impact of COVID-19 pandemic on medical staff in Guangdong, China: a crosssectional study. Psychol Med 2020;100:1-9. 
25 Rossi R, Socci V, Pacitti F, et al. Mental health outcomes among frontline and second-line health care workers during the coronavirus disease 2019 (COVID-19) pandemic in Italy. JAMA Netw Open 2020;3:e2010185.

26 Zandifar A, Badrfam R, Mohammadian Khonsari N, et al. COVID-19 and medical staff's mental health in educational hospitals in Alborz Province, Iran. Psychiatry Clin Neurosci 2020;74:499-501.

27 Liang Y, Chen M, Zheng X, et al. Screening for Chinese medical staff mental health by SDS and SAS during the outbreak of COVID-19. $J$ Psychosom Res 2020;133:110102.

28 Wang W, Song W, Xia Z, et al. Sleep disturbance and psychological profiles of medical staff and non-medical staff during the early outbreak of COVID-19 in Hubei Province, China. Front Psychiatry 2020;11:733.
29 Asaoka H, Koido Y, Kawashima Y, et al. Post-traumatic stress symptoms among medical rescue workers exposed to COVID-19 in Japan. Psychiatry Clin Neurosci 2020;74:503-5.

30 Virtanen M, Jokela M, Madsen IE, et al. Long working hours and depressive symptoms: systematic review and meta-analysis of published studies and unpublished individual participant data. Scand $J$ Work Environ Health 2018;44:239-50.

31 Song X, Fu W, Liu X, et al. Mental health status of medical staff in emergency departments during the coronavirus disease 2019 epidemic in China. Brain Behav Immun 2020;88:60-5.

32 Brandford AA, Reed DB. Depression in registered nurses: a state of the science. Workplace Health Saf 2016;64:488-511. 